Die Beobachtungen Dunecht Oct. 9, Rom Oct. $\mathbf{r} 7$ und Odessa Oct. 25 werden durch folgende elliptische Elemente genau dargestellt.

$$
\begin{aligned}
& \text { Mittl. Aeq. r } 88 \text { r.o. Epoche Oct. I 7.5. } \\
& M=3^{0} 39^{\prime} 3^{\prime \prime} 30 \\
& \pi=\text { r } 48 \text { 1 } 7.9 \\
& \delta=654149 \\
& i=64^{8} \text { ro.8 } \\
& \varphi=5^{6} 2022.4 \\
& \log a=0.6395640 \\
& \mu=3^{8} 9^{\prime \prime} 63^{82}
\end{aligned}
$$

Umlaufszeit 9.106 Jahre.

\section{Bemerkung: Der Durchang.}

Für die Beobachtung Marseille Oct. 5 bleibt noch ein Fehler von Beob.-Rechn.: $\mathrm{d} \lambda \cos \beta=+6{ }^{\prime \prime} 5 \mathrm{~d} \beta=+9 " 7$ übrig.

Wahrscheinlich ist der Comet Denning mit dem Cometen I8I9 IV, dessen Elemente bisher sehr ungenau berechnet sind, identisch. - Die Identität des letzteren mit dem Cometen von $1743 \mathrm{I}$ ist schon früher von Prof. Clausen (Astr. Nachr. X p. 345) als sehr wahrscheinlich erwiesen worden.

Der Comet Barnard konnte hier vorstehender Bäume wegen nicht beobachtet werden.

Odessa, I 88 I Nov. 12.

E. Block.

\title{
Ephemeride des Cometen 1881 III, (Fortsetzung zu A. N. 2399).
}

Herr Privatdocent F. Engström hat folgende Fortsetzung der Ephemeride des Cometen I88 I III gerechnet. Zwei Beobachtungen von Oct. 2 I und 27 zeigen, dass die Ephemeridencorrectionen sehr klein sind. Im November hat Engström ein Mal den Cometen gesehen, konnte aber wegen plötzlicher Trübung des Himmels keine vollständige Beobachtung erhalten. Der Comet war schwach, aber noch nicht schwierig zu beobachten. Hoffentlich wird man mit stärkeren Fernröhren ihm noch lange folgen können.

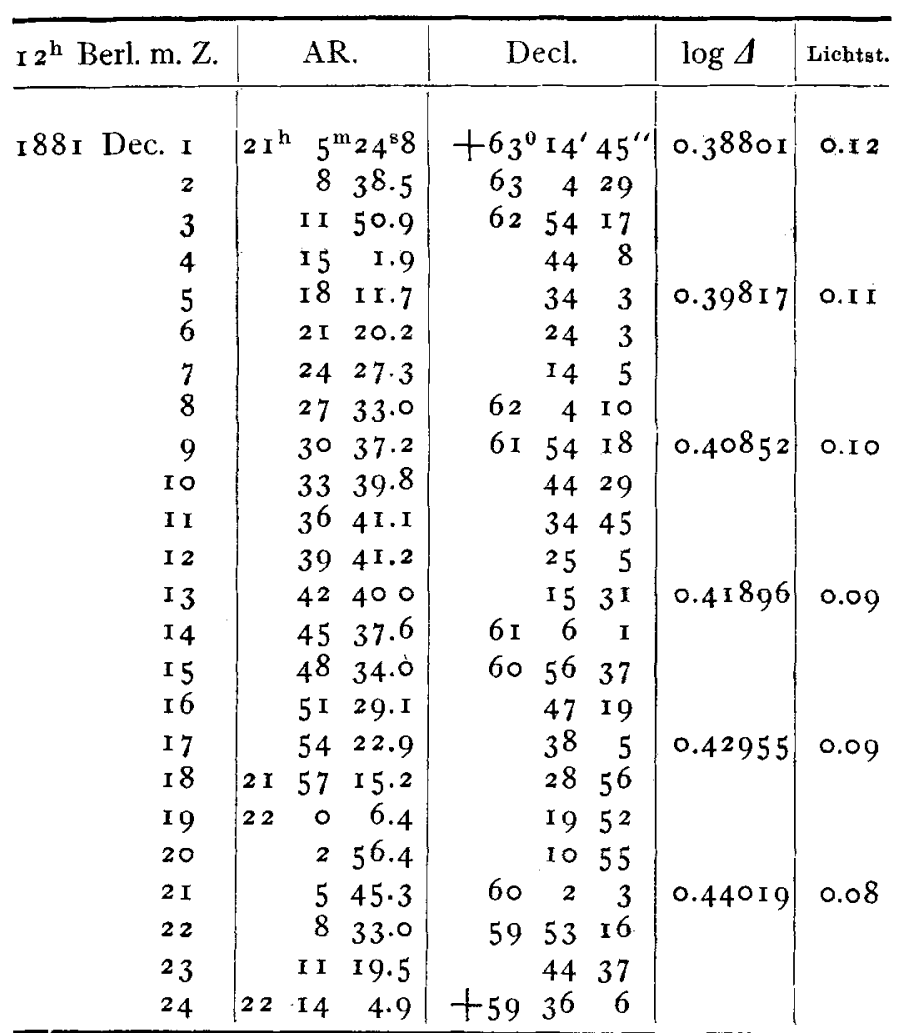

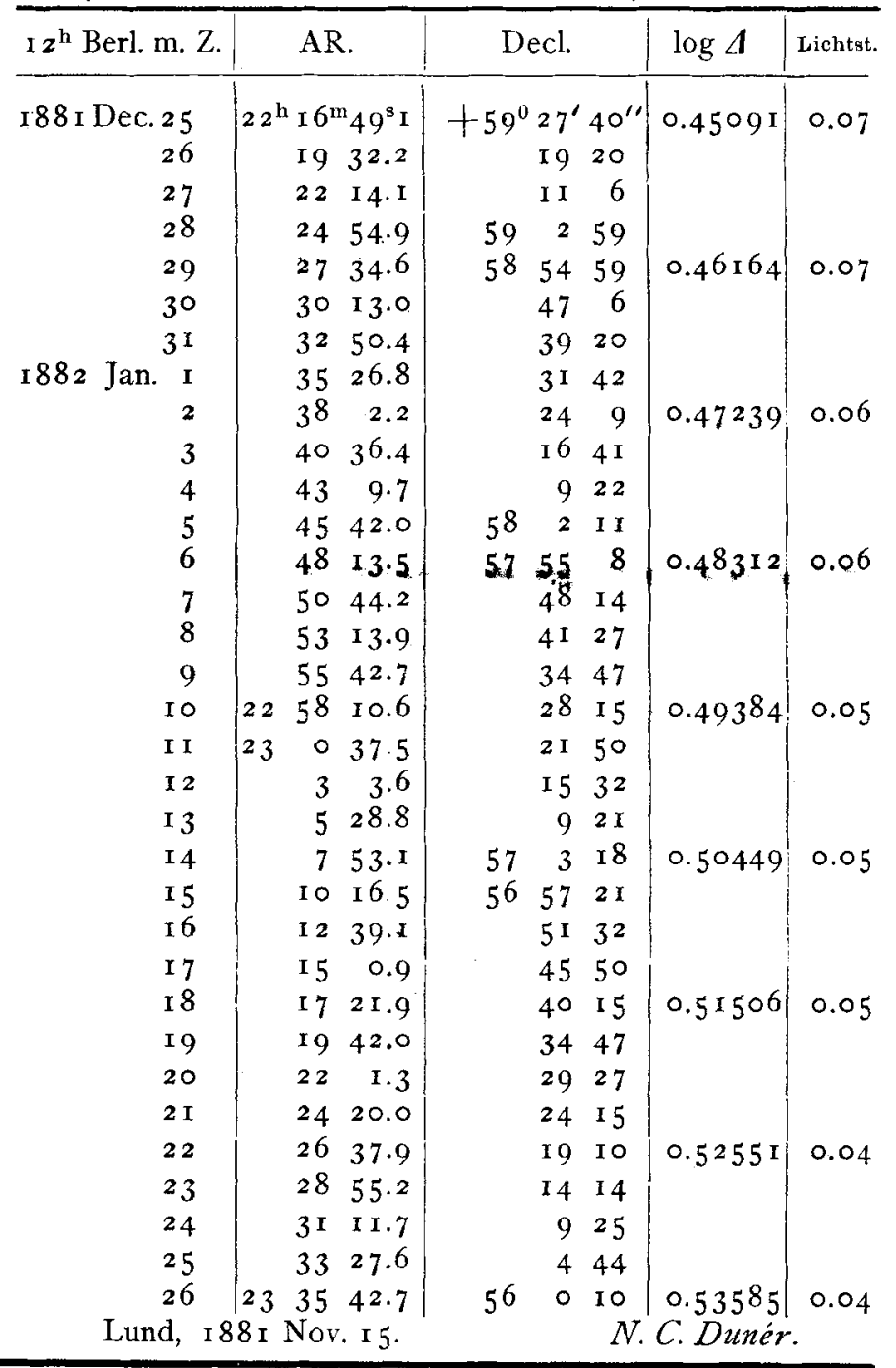

In hal t zu Nr. 2204. F. F. Fulius Schmidt. Ortsbestimmungen der Cometen I88I III und IV zu Athen 49. - - F. F. Fulizes Schmidt. Veränderliche Sterne. 55. - F. W. Fabritius. Ueber die Helligkeit des Cometen 188I III. 55. - E. Schönfeld. Bemerkung zu dem Artikel über die Eigenbewegung von LL. 22986 (W, 12hi24) in A. N. No. 2299. 57. - E. C. Pickering. Observations and Elements of Barnard's Come: 1881 ... 57. - B. Ptter. Beobachtungen des Cometen Barnard $188 \mathrm{r} \ldots$ und des Encke'schen Cometen auf der Leipziger Sternwarte. 59. - H. Kobold. Beobachtungen des Encke'schen Cometen am Kreismikrometer des 6 zölligen Merz'schen Refractors zu OGyalla. 61. - E. Block. Beobachtungen und elliptische Elemente des Cometen Denning i 88 I... 6I. - N. C. Dunír. Ephe-
meride des Cometen i881 III, (Fortsetzung zu A. N. 2399). 63. 